\title{
O IMPACTO DOS CUSTOS E DESPESAS NAS MICRO E PEQUENAS EMPRESAS
}

\section{ARTIGO ORIGINAL}

SILVA, Luiz Felipe Da Conceição ${ }^{1}$, CASTRO, Heveraldo Alves $\mathrm{De}^{2}$, ROBERTO, José Carlos Alves ${ }^{3}$, SERRA, Meg Rocha da Cunha ${ }^{4}$, LOPES, Nelânia Ferreira ${ }^{5}$

SILVA, Luiz Felipe Da Conceição. Et al. O impacto dos custos e despesas nas micro e pequenas empresas. Revista Científica Multidisciplinar Núcleo do Conhecimento. Ano. 06, Ed. 10, Vol. 04, pp. 55-69. Outubro 2021. ISSN: 2448-0959, Link de acesso: https://www.nucleodoconhecimento.com.br/contabilidade/custos-edespesas, DOI: 10.32749/nucleodoconhecimento.com.br/contabilidade/custos-edespesas

\section{RESUMO}

Dentre as características mais importantes dentro de uma entidade está o conhecimento de custos para produzir tal produto, e as despesas no que se refere aos gastos não relacionados com o produto final, mas sim, administrativas que as pequenas e microempresas possuem. O objetivo deste estudo é mostrar a relação que os custos e as despesas têm em relação aos principais fatores na economia do setor comercial, abrangendo empresas industriais, comércio, como fator de pequenas e microempresas. O estudo foi realizado através de pesquisas bibliográficas, artigos e livros a partir da pesquisa qualitativa. Para dar suporte ao estudo foi levantada a seguinte pergunta problema: por que o conhecimento dos custos e despesas são essenciais dentro de uma entidade? Conclui-se, portanto,

\footnotetext{
${ }^{1}$ Graduando do curso de Ciências Contábeis.

${ }^{2}$ Graduando do curso de Contabilidade.

${ }^{3}$ Orientador. Mestre em Engenharia de produção. Especialista Logística empresarial. Graduado em Administração com Ênfase em Marketing.

${ }^{4}$ Orientador. Mestra em Engenharia de Processos Industriais pela UFPA, especialista em Controladoria e Auditoria Contábil pelo Ciesa, Graduada em Ciências Contábeis pelo Centro Universitário do Norte. Graduada em Ciências Econômicas pelo Centro Universitário do Norte.

${ }^{5}$ Orientador. Especialista em Auditoria Contábil, Financeira e Tributaria e Graduada em Ciências Contábeis.
}

RC: 98899

Disponível em: https://www.nucleodoconhecimento.com.br/contabilidade/custos-edespesas 
que como uma parte da contabilidade, mas como campo de conhecimento por si própria, a contabilidade de custos é uma excelente adição ao arsenal do contador. A possibilidade de previsibilidade e análise da receita que poderá ser obtida de uma produção já é o suficiente para determinar isso; logo, o objetivo inicial do estudo foi atingido, deixando uma sucinta introdução ao campo da contabilidade de custos.

Palavras-chave: Gestão de custos, Despesas, Tomada de decisão.

\section{INTRODUÇÃO}

As empresas encontram-se em um ambiente de mudanças devido às mudanças que surgem todos os dias e a apuração correta de custos e despesas está entre os principais benefícios que pode-se mencionar no que diz respeito a margem de contribuição por produto que a empresa obtém porque o faturamento do seu produto pode ser caracterizado com o custo de sua produção ou compra. Além disso, a contabilidade de custo nada mais é do que uma subdivisão da Contabilidade Geral de uma empresa. Dando continuidade, foi questionado a seguinte pergunta problema: por que o conhecimento dos custos e despesas são essenciais dentro de uma entidade? Relacionado com estudos feitos por meio de gastos, ela se dedica para um bem que se consiga, de vendas ou de consumo, como por exemplo, serviços ou mercadorias. Seu principal objetivo é registrar operações das empresas, por meio de contas e custeio. Ela controla e registra a movimentação dos componentes do custo, ou melhor, dos fatores da produção. Silva (2017); Carmo (2012); Martins (2003); Ribeiro (2017) relatam a possibilidade de previsibilidade e análise da receita que poderá ser obtida de uma produção já é o suficiente para determinar isso; logo, o objetivo inicial do estudo foi atingido, deixando uma sucinta introdução ao campo da contabilidade de custos.

Dentro de uma organização, se estabelece parâmetros para tal diversidade, na busca de um bom resultado operacional. Com isso, entra o custo no início do produto, que se relaciona basicamente com atividade do negócio, precisamente 
como matéria-prima. Entretanto, entra um fator primordial que é as despesas, que não se refere ao produto, mas sim com as despesas administrativas.

Como definição de despesa, ela engloba todos os gastos relativos à administração da empresa, por meio de pontos comerciais, de slogan, e de desenvolvimento de produtos. Ou seja, se caracteriza para manter a estrutura funcionando, porém, não agem diretamente para a produção de novos itens para serem vendidos e comercializados. As despesas estão relacionadas com os gastos usados para a obtenção de receitas.

São entendidos como despesa, os gastos com salários, telefone, propaganda, comissão de vendedores, entre outros. Alguns exemplos podem ser citados nas despesas, que são as contas de luz e água, aluguel de prédio, materiais de escritórios e gastos com estrutura. Já os exemplos de custos são a matéria-prima, mão de obra, gastos gerais de fabricação e a depreciação de máquinas.

Portanto, este estudo propõe mostrar a relação que os custos e as despesas têm em relação aos principais fatores na economia do setor comercial, abrangendo empresas industriais, comércio, como fator de pequenas e microempresas. Bem como descrever a análise de custos, entender como funciona a análise de custos dentro das pequenas e microempresas. $O$ estudo foi realizado a partir de pesquisas bibliográficas a partir de material existente.

\section{FUNDAMENTAÇÃO TEÓRICA}

A fundamentação teórica é, de forma geral, uma revisão feita de discussões e pesquisas para a obtenção de estudos referentes ao tema a ser abordado no trabalho. Além disso, se relaciona com as contribuições das teorias de outros autores para a pesquisa. Ela serve como um embasamento teórico para a pesquisa que será desenvolvida ao longo do estudo. 


\subsection{BREVE HISTÓRICO DA CONTABILIDADE DE CUSTOS}

Com base em meios da Revolução Industrial, houve um grande índice de necessidade de registros, análise e controle da movimentação financeira, de um protótipo de contabilidade financeira. A existência dos pequenos produtores e fornecedores de serviço deixava de lado o manejo da movimentação contábil. Contudo, com o surgimento das primeiras empresas, tal fator foi deixado de lado.

Diferentemente do mercantilismo, o contador se via na necessidade de novos meios de contabilizar os meios em produção empresarial, agora dada em larga escala. Antes, bastava verificar o valor pago pelo item no estoque e, juntamente com um simples inventário no final do período, o cálculo do lucro da empresa era feito em cima do valor pago na saída do produto. Agora, por meio da indústria, a função do contador se torna mais complexa e necessária. A presença de diferentes gastos, em diferentes etapas da produção, gerava discrepâncias no cálculo final do lucro da empresa. O contador não dispunha dados referentes à empresa na qual viesse infligir os valores do estoque. Seu valor de compra era substituído por uma série de valores pagos pelos fatores de produção (MARTINS, 2003).

Existem áreas da Contabilidade de Custos pouco exploradas, que podem ser aproveitadas em segmentos deficientes de outras áreas (administrativa, financeira e econômica), oferecendo melhores subsídios para uma boa administração. Segundo Leone (2012), o tema se caracteriza por ser uma atividade gerada por grandes processos de informações, na qual há uma grande junção com um centro processador. Além disso, acumula e obtém dados de forma organizada, para que se haja um fornecimento de sugestões para a tomada de decisões.

É importante notar que houve um grande avanço na produção, na qual foi seguida de perto pelo aprofundamento da ciência contábil. Os métodos necessários para atribuição do produto, com relação ao preço, na qual precisaram evoluir, juntamente com a especificação dos processos envolvidos na fabricação do produto final. Outro fator importante é a separação das despesas, uma vez que, agora, o valor final do

RC: 98899

Disponível em: https://www.nucleodoconhecimento.com.br/contabilidade/custos-edespesas 
produto poderia ser composto a partir de despesas indiretas, como o gasto com o manejo de recursos humanos para a mão de obra. Tal separação se deu, de maneira resumida, em despesas administrativas, de vendas, financeiras e de produção; da última, tem-se o protótipo do que hoje é conhecido como contabilidade de custos.

Houve uma grande ênfase por parte de Auditores e Contadores, no que se refere a contabilidade de custo, para se tratar dos estoques, resultados e mensuração monetária. Entretanto, a contabilidade de custos, em si, não era vista como uma ciência, fazendo uma ponte entre a matemática e a administração cotidiana. Logo, a epifania de sua utilização era para se tratar de tomada de decisões, controle da empresa etc. se deu apenas séculos depois.

Dentro da Contabilidade de Custos, faz-se necessário classificar os custos e se diferenciar os sistemas e métodos a serem usados. Cada empresa tem seus objetivos e finalidades a serem desenvolvidas, na qual basta analisar e verificar de forma correta qual o método de custo é o que mais se enquadra com o que a empresa necessita. A contabilidade de custos não teve uma grande evolução acentuada por muito tempo, visto que a nova visão de custo deve ser muito lembrada, pois data mais que décadas, na qual pode se desenvolver algo mais sobre pesquisas e estudos científicos. Existe uma finalidade básica quando a contabilidade de custos foi criada, e o não oferecimento de dados.

Com a atual situação da tecnologia, e seu abrangente uso na contabilidade e administração de empresas, a contabilidade de custos é uma ferramenta extremamente útil na tomada de decisões e no controle da empresa. Os dados fornecidos através destes métodos contábeis facilitam a situação de gastos desnecessários, permitindo um melhor planejamento contábil e empresarial; o feito por meio de decisões, quando embasadas em uma análise contábil eficiente, é embasada em um processo científico e metódico, que toma os dados correntes e não extrapola para a especulação. 
A definição de forma simples da diferença de custo e despesa, na qual diz que que o custo pode se caracterizar como atividade fim do negócio (matéria-prima), como um gasto para se colocar o produto na prateleira, e já a despesa se diz a respeito do gasto para se levar o produto até o cliente final (MORANTE; JORGE, 2009).

\subsection{TERMINOLOGIA}

Apesar de sinônimos no entendimento comum, as palavras "gastos", "custos" e "despesas" adquirem significados diferentes no patamar contábil. Logo, a boa definição delas é essencial para o bom desenvolvimento do trabalho. Entender-se-á gasto como adquirir o produto e serviço, que gere desembolso para a entidade; custo, que seria a soma de produtos e gastos incorridos, na qual fazer parte de outros procedimentos necessários, como aquisição, conversão e entre outros. Por fim, despesa, que venha ou que possa ser um serviço ou bem, de matéria consumidora, que influi direta ou indiretamente (CARMO, 2012).

Para Colpo (2012) todas as despesas são gastas, entretanto não se transformam em despesas, como por exemplo um terreno, que não se torna uma depreciação, ou só se torna depreciado quando há venda. Outra característica é entre desembolso e perda. O primeiro é um pagamento voluntário, em vista de utilidade comprada; o segundo é involuntário, anormal, feito sem a intenção de obtenção de receita, o que também difere o desembolso de investimento, o que é feito visando benefícios futuros.

Apesar da terminologia apresentar uma definição simples, a separação entre as duas modalidades de gastos, numa situação real, envolve a análise da influência deste sobre o produto prestado. A separação em si, portanto, é uma tarefa que necessita da atenção do contador, e da transparência da entidade; se bem realizada, implica em uma análise de custos acurada, e se realizada em cima de informações desatualizadas, ou falsas, implica em uma análise defasada.

RC: 98899

Disponível em: https://www.nucleodoconhecimento.com.br/contabilidade/custos-edespesas 


\subsection{PONTO DE EQUILÍBRIO}

Após a separação devidamente feita, a análise de como o custo ou despesa do serviço prestado, se dá através de ferramentas matemáticas. A razão da variação do custo final do produto, e o lucro que ele irá gerar, pode influir diretamente na empresa. Uma destas ferramentas é o ponto de equilíbrio, que, em termos chulos, representa o mínimo de receita gerada que cobrirá seus custos e despesas fixas. A característica principal do ponto como momento em que o valor das vendas é necessário para suprir feitos. Neste momento, a razão da empresa é igual a zero (BERBEL, 2003). O ponto de equilíbrio como sendo a equação $R T=C F+C V$, onde as receitas totais (RT) são a soma dos custos fixos (CF) com os custos variáveis (CV).

O seguinte exemplo, retirado da empresa Cia. Industrial Polinésia S/A, apresentou os seguintes dados e projeções acerca da produção:

Tabela 1: Dados contábeis acerca da produção

$\mathrm{R} \$ 100,00$ Preço de Venda Unitário (PV/u)

$(\mathrm{R} \$ 60,00) \quad$ Custo e Despesa Variável Unitário (CDV/u)

$\mathrm{R} \$$ 40,00 Margem de Contribuição Unitária (MC/u)

$R \$ 200,00 \quad$ Custos e Despesas Fixas (CDF)

Fonte: adaptado pelo autor (2021).

RC: 98899

Disponível em: https://www.nucleodoconhecimento.com.br/contabilidade/custos-edespesas 
Tabela 2: Projeção de Produção

\begin{tabular}{l|cccccccc} 
Unidades & 0 & 1 & 2 & 3 & 4 & $\mathbf{5}$ & 6 & 7 \\
\hline Vendas (R\$) & 0 & 100 & 200 & 300 & 400 & $\mathbf{5 0 0}$ & 600 & 700 \\
CDV (R\$) & $(0)$ & $(60)$ & $(120)$ & $(180)$ & $(240)$ & $\mathbf{( 3 0 0 )}$ & $(360)$ & $(420)$ \\
MC (R\$) & 0 & 40 & 80 & 120 & 160 & $\mathbf{2 0 0}$ & 240 & 280 \\
CDF (R\$) & $(200)$ & $(200)$ & $(200)$ & $(200)$ & $(200)$ & $(\mathbf{2 0 0})$ & $(200)$ & $(200)$ \\
Total & $(200)$ & $(160)$ & $(120)$ & $(80)$ & $(40)$ & $\mathbf{0}$ & 40 & 80
\end{tabular}

Fonte: adaptado pelo autor (2021).

A sexta coluna indica o momento em que vai haver uma maior produção e iria gerar receita o bastante para cobrir os seus custos fixos e variáveis; ou seja, produzindo 5 unidades do produto, a empresa iria atingir o seu ponto de equilíbrio, e sua contribuição seria positiva. Como o próprio autor indica, realizar esse processo para todas as entidades seria penoso. Assim, o feito de métodos e a análise dos gráficos gerados pela Margem de Contribuição Unitária e das despesas e custos são de vital praticidade para a contabilidade de custos.

Como bem descrito por Raimundini et al. (2008), a matemática por trás desta formulação é simples, e é utilizada de maneira geral sem muitos pré-requisitos. Em suma pode ser atingido, em função da quantidade produzida pela empresa por meio da fórmula: $P E(q)=M C / u$ CDF, ou ainda, em função do valor, $P E(\$)=M C / u$ CDF. Desta maneira, se a empresa PV/u indicasse os seguintes dados:

RC: 98899

Disponível em: https://www.nucleodoconhecimento.com.br/contabilidade/custos-edespesas 
Tabela 3: Custos

\section{Vendas $(100.000$ unid. $\times 8,00)$ \\ CDV (100.000 unid. $\times 4,00)$ \\ Margem de Contribuição \\ Custos e Despesas Fixas \\ Lucro Líquido}

$800.000,00$

$(\underline{400.000 .00)}$

$400.000,00$

$(\underline{160.000,00)}$

$\underline{240.000,00}$

Fonte: Berbel (2003).

O Ponto de Equilíbrio, em relação à quantidade, seria com 40.000 unidades; e em relação ao valor, $\mathrm{R} \$ 320.000,00$. Tal resultado seria aferido pela Demonstração de Resultado do Exercício (DRE), onde o resultado seria zero.

Tabela 2: DRE referente a 40 mil unidades produzidas

Vendas $(40.000$ unid $\times \$ 8,00)$

(-) Custos e Despesas Variáveis (40.000 unid.×4,00) $\quad(\underline{160.000)}$

Margem de Contribuição

160.000

(-) Custos e Despesas Fixas

$(\underline{160.000)}$

Resultado

0,00

Fonte: adaptado pelo autor (2021).

\subsection{ANÁLISE DE CUSTOS}

A presença de informações contábeis confiáveis, durante a tomada de decisão, é importante para o bem-estar econômico da entidade. A análise contábil exerce papel preventivo, nas projeções de produção e venda das empresas, e papel controlador, nos fechamentos contábeis, auditorias e inventários. Em especial, a análise de custos exerce papel fundamental na produção ou realização de serviços da empresa, pois permite uma visão rápida e precisa acerca do panorama da empresa. 
No artigo publicado, Schaedler et. al. (2021) realizaram uma pesquisa acerca da utilidade e praticidade da contabilidade; o diferencial dessa pesquisa é ter sido feita pela visão dos gerenciadores. A obtenção de respostas através de questionário, podem ser compreendidas por meio de dados na visão dos gestores. Outra característica que pode ser estabelecida, é que com relação a ferramenta do planejamento estratégico, quase todos os empresários conhecem, entretanto não utilizam de forma correta.

Portanto, é indiscutível a necessidade da contabilidade, como ferramenta de escolher certas decisões. Como no exemplo discutido na seção anterior, uma empresa se beneficia facilmente da adoção desses métodos: uma previsibilidade acerca do ponto permite à empresa decidir quanto tempo será para cobrir o custo de produção do bem da organização (produtos ou serviços); se tal ferramenta não fosse útil o bastante, também permite o estudo de "quão caro" é para produzir o bem da empresa. Se alguma decisão tomada sobre esses assuntos, como bem afirmado no artigo citado acima (RIBEIRO, 2017).

Esses rateios são o ponto principal da análise de custos, e permitem que a sociedade empresarial visualize os custos de maneiras diferentes, para diferentes usos. O segundo, está apropriado em quaisquer tipos de produção gerada por custos, na qual são fixos ou variáveis, diretos ou indiretos, partindo para a elaboração de produtos. Com o mesmo seguimento do autor, os custos fixos ficam distantes das variáveis (SILVA, 2017).

O sistema $A B C$ é mais amplo e pode ser descrito como uma ferramenta de gestão de custos e não somente um modo de custeio. Ao invés de calcular o custo sobre o bem-produzido, o cálculo é realizado sobre os processos que envolvem essa produção. Entretanto, a ação feita de uma nota fiscal é realizada pelo setor financeiro, mas pode incluir etapas burocráticas de outros setores, almoxarifado, compras, quanto mais processos interdepartamentais ocorrerem na empresa, maiores serão os suportes positivos do ABC.

RC: 98899

Disponível em: https://www.nucleodoconhecimento.com.br/contabilidade/custos-edespesas 


\subsection{GESTÃO DE CUSTOS E DESPESAS EM MICRO E PEQUENAS EMPRESAS}

Conforme a Lei Complementar de ํㅜ 123, instituída em 14 de dezembro de 2006, considera microempresas (ME) ou empresas de pequeno porte (EPP), os tipos de sociedades envolvendo a sociedade simples, sociedade empresa, e a empresa individual de responsabilidade limitada e o empresário que, no caso da microempresa, se tratando do calendário anual, que se pode obter uma receita bruta igual ou inferior a $\mathrm{R} \$ 360.000,00$.

As micro e pequenas empresas estão em um contexto importante no que diz respeito a economia do país. Além disso, possui participação relevante na distribuição de deduções de renda e mobilidade social, pois permite suprir os produtos e serviços, desempenhando um papel importante para a redução de desequilíbrios regionais. Observa-se que, na capital do Amazonas, grande parte do mercado é formado por micro e pequenas empresas, muitas vezes informais, mas que fazem parte do cotidiano manauara.

A contabilidade relacionada aos custos é utilizada abertamente por países de primeiro mundo como EUA, Nova Zelândia, Canadá etc. A presença desta na administração pública, bem-sucedida aliás, mostra a competência que ela apresenta. Não somente isso, é muito importante no ramo da saúde e agricultura (MAUSS, 2015).

As empresas comerciais de menor porte também são proveitosas. De fato, SENAI, SENAC, Fundação Bradesco e Getúlio Vargas oferecem, de maneira gratuita ou paga, cursos de metodologia de custos; tais portais de educação são voltados para o meio comercial e industrial brasileiro. Não somente útil, em geral, o método de custeio também é necessário, na perspectiva econômica atual: a crise do COVID-19 abalou a maneira como o mundo compra e vende. Pesquisas realizadas pelas empresas Ebit/Nielsen e MasterCard mostram um interesse do mercado no E- 
commerce. Este mercado, que apresenta grande praticidade e fácil inserção, apresenta uma contabilização diferente à empresa.

Entre as quatro principais entidades provedoras de internet no Amazonas (Oi, Net, Tim e Sky), o preço médio dos planos iniciais de internet é de $R \$ 106,00$. Esse custo fixo, mas com possibilidade de variação (atraso, manutenção etc.) é um custo que pode ser considerado com os já adotados pela empresa. Fora este detalhe, a menos que a sociedade não terceirize seu serviço de entrega, o valor de entrega pode variar enormemente. De maneira municipal, muitos entregadores praticam a entrega informal, onde recebem uma comissão por entrega feita. De maneira formal, a empresa Uber já oferece meios diferenciados de entregas elogiado, esta opção, todavia, apresenta um custo de variância muito maior que a primeira, pois o sistema da empresa calcula seus valores em cima do clima e a condição do trânsito.

Nesta ingênua análise, fica notável a necessidade da utilização da contabilidade de custos, para remediar a imprevisibilidade do mercado, através de metas realistas e que atendem à necessidade do empreendedor. Não somente através da internet, mas o relatório publicado pelo Ministério da Economia (BRASIL, 2020) mostra uma presença maior de empresas, em todos os mercados. Mercados estes também abalados, tanto pela inconsistência do auxílio fornecido pelo governo, quanto pela inflação de preços, se beneficiaram da utilização da contabilidade de custos também.

\section{MATERIAIS E MÉTODOS}

O método significa o caminho por qual seguir mediante séries de operações e regras pré-fixadas para assim poder alcançar os resultados propostos. Visto que, a metodologia segue algumas etapas, por isso dependerá do pesquisador quais métodos e materiais serão utilizados em sua investigação. Diante disso, no entendimento de a metodologia se define, de maneira operacional, como o estudo crítico do método, ou bem como a lógica particular de uma disciplina (SANTANCHÉ, 2015).

RC: 98899

Disponível em: https://www.nucleodoconhecimento.com.br/contabilidade/custos-edespesas 


\subsection{PROCEDIMENTOS METODOLÓGICOS}

Os procedimentos metodológicos de fato correspondem a um conjunto de tomada de decisões e ações quanto à escolha de técnicas de pesquisas e métodos para um desenvolvimento de um trabalho científico. Também chamado de percurso metodológico (SEVERINO, 2017). Inicialmente, será discutido o embasamento teórico do problema, utilizando como principal definição de custos e despesas, tal discussão servirá para introdução ao restante do trabalho. Dada esta discussão, a análise de tais movimentações contábeis será foco da próxima etapa do trabalho. A conclusão dele será a praticidade e utilidade que tais análises apresentam ao administrador.

\subsubsection{QUANTO À NATUREZA}

Segundo Gil (2017), o conhecimento obtido por meio de pesquisas tem a característica de entrar em uma lacuna de conhecimento. A pesquisa será realizada de forma qualitativa, pois terá como objeto de estudo artigos científicos que se relacionem com a temática do estudo.

\subsubsection{QUANTO AOS FINS}

Toda pesquisa é realizada com um propósito determinado que, de acordo com Zanella (2017), a pesquisa exploratória tem como base e objetivo proporcionar uma facilidade em buscas de encontrar soluções para o problema, para tornar mais explícito ou relacionar uma construção de hipóteses obtidas por meio da pesquisa em si. O levantamento de dados bibliográficos, como descrito no início desta seção, levará ao campo acadêmico um material objetivo e claro, de maneira a facilitar a abordagem do assunto. Desta maneira, este manuscrito se encaixa na descrição de pesquisa exploratória descritiva.

RC: 98899

Disponível em: https://www.nucleodoconhecimento.com.br/contabilidade/custos-edespesas 


\subsubsection{QUANTO AOS MEIOS}

Segundo Gil (2017), os tipos de pesquisa são caracterizados por meio de material já existente, encaixando principalmente livros e artigos e materiais publicados. A análise dos pesquisadores será realizada em cima de conhecimento já desenvolvido. Logo, a utilização completa de fontes bibliográficas já existentes é a melhor forma para a obtenção dos objetivos definidos anteriormente.

\subsubsection{QUANTO A ABORDAGEM}

Segundo Pereira (2018), a influência dos métodos qualitativos é considerada muito importante para a visão do pesquisador, na qual formula suas opiniões a respeito do tema estudado. Dada a problemática optada, o método qualitativo será a abordagem desta pesquisa.

Pois, diante da quantidade de artigos em contabilidade publicados antes da pandemia, uma análise criteriosa deles deverá ser feita, antes da aplicação factual; tal análise, oriunda dos autores, se encontrará entre os resultados do trabalho, juntamente com dados qualitativos obtidos dos artigos estudados.

\section{CONSIDERAÇÕES FINAIS}

Através deste estudo conclui-se que com relação aos custos e despesas é de extrema importância o conhecimento, na qual traz grandes resultados e diferenças no modo gerencial e organizacional da empresa em geral. Através dos dados expostos no trabalho, foi possível calcular e compreender alguns pontos importantes para algumas análises. O ponto de equilíbrio é o limite que separa lucro de prejuízo. Para uma empresa, conseguir atingir seu ponto de equilíbrio e custear suas despesas mensais é de suma importância.

Partindo em diante para a resposta da pergunta problema, pude concluir a possibilidade de previsibilidade e análise da receita que poderá ser obtida de uma 
produção que já é o suficiente para determinar isso; logo, o objetivo final do estudo foi atingido, deixando uma sucinta conclusão ao campo da contabilidade de custos.

Contudo, as micro e pequenas empresas (MPEs) se relacionam com o impacto da economia, por meio de suprimento de serviços e produtos, desempenhando um papel importante para a redução de desequilíbrios regionais. Observa-se que, na capital do Amazonas, grande parte do mercado é formado por micro e pequenas empresas, muitas vezes informais, mas que fazem parte do cotidiano manauara. A utilização da contabilidade para tomada de decisões não é assunto de discussão. Sua extensa gama de ferramentas, que abrange da matemática ao direito constitucional, exerce grande papel analítico e qualitativo nas questões empresariais. Todavia, fica claro, com este trabalho, que o uso da contabilidade de custos para fins de tomada de decisão é de vital importância para o micro e pequeno empreendedor.

O ponto de equilíbrio fornece uma poderosa ferramenta para a previsão de custos sobre a produção; os modos de custeio podem ser utilizados para modificar a forma como uma empresa visualiza seu caminho de produção; a própria nomenclatura utilizada na contabilidade de custos auxilia na administração das empresas. Enfim, diversos benefícios podem ser encontrados na análise feita nos ramos do mercado, entre eles, mas não se resumindo, os setores hospitalar e de agricultura.

Portanto, não só como uma parte da contabilidade, mas como campo de conhecimento por si próprio, a contabilidade de custos é uma excelente adição ao arsenal do contador. Logo, o objetivo inicial dele é atingido, deixando uma sucinta introdução ao campo da contabilidade de custos.

\section{REFERÊNCIAS}

BERBEL, J. D. S. Introdução à contabilidade e análise de custos: simples \& prático. São Paulo: Editora STS, 184 p. 2003. Atualizado em março de 2017. 
Disponível em: <http://www.berbel.pro.br/Livro\%20-\%20Ultima\%20edicao.pdf>. Acesso em: 22 maio 2021.

BRASIL. Departamento Nacional de Registro Empresarial e Integração. Ministério da Economia. Mapa de Empresas: boletim do 3ํquadrimestre/2020. 2021.

CARMO, C. R. S.; et al. Métodos quantitativos aplicados à análise de custos em micro e pequenas empresas: um estudo de caso realizado em uma empresa do setor varejista de autopeças. In: Anais do Congresso Brasileiro de CustosABC. 2012.

COLPO, I.; et al. Análise do custo-volume-lucro auxiliando na tomada de decisão: o caso de uma microempresa/Analysis of cost-volume-subsidy profit in the decision-making: the case of a micro-company. Revista da micro e pequena empresa, v. 9, n. 3, p. 22, 2015.

GIL, A. C. Como Elaborar Projetos de Pesquisa. 6 ed. São Paulo: Atlas, 2017.

LEONE, G. G. Custos: planejamento, implantação e controle. 3 ed. São Paulo: Atlas, 2012.

MARTINS, E. Contabilidade de Custos. 11. ed. São Paulo: Atlas, 2003.

MAUSS, C. V.; et al. A gestão de custos como instrumento da eficiência pública no brasil e em outros países. Revista Eletrônica de Administração e Turismo, Pelotas, v. 6, n. 3, p. 595, 2015.

MORANTE, A. S.; JORGE, F. T. Formação de preços de venda: preços e custos, preços e composto de marketing, preços e concorrência, preços e clientes. São Paulo: Atlas, 2009.

PEREIRA, A. S. et al. Metodologia da Pesquisa Científica. Santa Maria: UFSM, NTE, p. 23, 2018. 
RAIMUNDINI, S. L.; et al. Ponto de equilíbrio e otimização sob a perspectiva da matemática. Enfoque: Reflexão Contábil, Paraná, v. 27, n. 2, p. 39-55, 2008.

RIBEIRO, O. M. Contabilidade de custos. Saraiva Educação SA, 2017.

SANTANCHÉ, A. Construção do conhecimento e Metodologia Científica. Jaboatão dos Guararapes - PE: UNIGF, 2015.

SEVERINO, A. J. Metodologia do Trabalho Científico. ed. 02, São Paulo: Cortez, 2017.

SCHAEDLER, L. R.; et al. A eficiência das informações contábeis na tomada de decisão em micro e pequenas empresas. Brazilian Journal of Development, Vol. 7, No. 4, 2021.

SILVA, J. A. D.; et al. A importância da gestão de custos como diferencial para micro e pequenas empresas. Revista Eletrônica Organizações e Sociedade, v. 5, n. 4, p. 79-92, 2017.

ZANELLA, L. C. H. Metodologia de Pesquisa. ed. 02, Florianópolis: Departamento de Ciências da Administração/UFSC, p. 24, 2013.

Enviado: Setembro, 2021.

Aprovado: Outubro, 2021.

RC: 98899

Disponível em: https://www.nucleodoconhecimento.com.br/contabilidade/custos-edespesas 